\title{
The Relationship between Teaching Quality and Academic Engagement in Medical Students: a descriptive-correlational study
}

\section{Amin Haghgoo}

Saveh University of Medical Sciences

Hadi Asady

Saveh University of Medical Sciences

Elahe Gholamhosseini

Saveh University of Medical Sciences

\section{Bahram Armoon}

Saveh University of Medical Sciences

Amir-Hossein Bayat ( $\square$ ah.bayat@yahoo.com )

Saveh University of Medical Sciences https://orcid.org/0000-0002-3784-0527

\section{Research article}

Keywords: Nursing Education Research, Academic Success, School Teachers, Students, Nursing

Posted Date: June 6th, 2019

DOI: https://doi.org/10.21203/rs.2.10094/v1

License: (c) (1) This work is licensed under a Creative Commons Attribution 4.0 International License. Read Full License 


\section{Abstract}

Background: One of the essential activities in improving the quality and effectiveness of teaching is to pay attention to the quality of teaching and engagement of students in their academic process. Thus, the aim of this study was to determine the relationship between teaching quality and academic engagement among Iranian nursing students.

Methods: This is a descriptive-correlational study. The present study was carried out on 124 anesthesia and operating room nursing students who were selected using simple random sampling in the year 2017. The research tools included standard demographic, course experience, and academic engagement questionnaires. Data analysis was carried out using descriptive tests, independent t-test, and Pearson correlation in SPSS ver. 24.

Results: The results of Pearson correlation analysis on the relationship between the subscales of teaching quality, including good teaching, clear goals, appropriate assessment, appropriate workload, independence, and generic skills with academic engagement showed a statistically significant relationship between all remaining subscales, except for the proper workload sub-scale $(P=0.234)$.

Conclusion: The results of this study showed a significant positive correlation between the course experience and academic engagement. Therefore, steps can be taken to improve the quality of the educational system using active and student-centered teaching methods.

\section{Background}

The highest level of education in each country is university education. Therefore, necessary and effective steps should be taken to promote qualitative development along with quantitative development. Overall, paying attention to the quality is essential for the dynamism and focus of the higher education system, and any success in this regard will lead to an increase in efficiency and productivity [1]. The concept of quality in the higher education system includes different meanings [2]. The quality of teaching and learning is one of the most important quality dimensions in the higher education system [3]. Quality in the teaching field means the degree of adaptation and compatibility of each indicator and main attribute of the teaching quality with desirable standards and qualities mentioned in various theories [4]. According to Marsh et al., the teaching quality can make the learning effective. It includes general teaching and learning components and is often related to higher education settings [5]. Academic engagement is one of the most important indicators of the quality of education, teaching, and academic achievement [6]. Richardson (2005) studied the educational experience of students with some subscales such as good teaching, standard and clear goals, appropriate assessment, appropriate homework and improvement of general skills [7]. Janus et al. (2000) showed that variables associated with course experience are the best anticipators to meet academic achievement [8].

Academic engagement is a construct that was first introduced to understand and explain academic failure and considered as the basis for reformist efforts in the education field [9]. In general, there are 
three dimensions of engagement, which can be considered as an academic engagement: Vigor is characterized by high levels of energy and mental resilience while working, and the willingness to do a specific job. Dedication is characterized by high passion and enthusiasm for doing something or encountering a subject. Absorption is characterized by intense focus on doing a job so that the person does not feel the passage of time during that job, as if both body and mind are so focused on it which can be defined as "being overwhelmed by the joy of doing a job" according to its specialized term in psychology [10]. The literature review has shown that learners who have more passion, enthusiasm, mental resilience to do their assignments enjoy higher academic achievement [11]. The academic engagement also involves behavioral, cognitive and emotional dimensions [12]. Behavioral dimension refers to visible academic behaviors, such as effort and sustainability when facing problems during classroom assignments and the demand for assistance from faculty members or classmates in order to learn and understand the textbook materials [13]. The vigor construct refers to the behavioral dimension of the engagement [10]. The emotional dimensional engagement of this type of engagement addresses the learner's emotional reactions in the classroom and university [14]. Emotional engagement involves internal interest in content and homework, valuing the textbook materials, having a positive effect, and lack of negative affects such as despair, anxiety, and anger while doing homework and learning [15]. Sacrifice is, in fact, an emotional component of the engagement[10]. However, cognitive engagement includes different types of processing processes that learners use to learn and consists of cognitive and metacognitive strategies. The absorption construct is considered as the cognitive dimension of the engagement [16]. In other words, academic engagement is a flexible state formed by the university's environment [17]. Academic engagement involves a variety of practices. For example, the amount of student engagement in doing homework[18], the amount of academic activities and being active in the classroom [19], the extent of the learner's effort in conducting targeted educational activities [20], and their compatibility with the culture governing the university and the effective communication with their teachers and classmates [21]. Janoos et al. showed in their research that the academic engagement is closely related with academic factors to the extent that even students who are interested in studying drop out due to negative academic factors [22]. Shana et al. (2015) also showed in their study the academic engagement could be useful in enhancing student learning and educational settings [23]. In the meantime, intra-university interactions such as student-professor interaction, student-student interaction, and student interaction with other educational bodies affect the level of academic engagement [24]. Therefore, the turning point of this effect is to choose the teaching style of the faculty, and they should be fully aware of their teaching styles and their impact on student learning [25].

Golshan pointed to a high drop rate in higher education in the country and referred to the professors' quality of teaching as the most important factor in this regard [26]. Fenn states in a study that most of the determinants of teaching quality based on the learners' assessment of the teaching quality include organization, transparency of material presentation, instructor availability, and professor's level of motivation [27]. Therefore, the attention and recognition of the views of learners about the level and importance of teaching quality components provide the appropriate feedback for analyzing educational issues and strategic planning for higher education professors and staffs, on the one hand. On the other 
hand, instructors will be able to modify teaching methods and thus improve their teaching quality by understanding the importance of academic engagement and its role in educating and empowering the learners. In other words, it is assumed in this study that the teaching quality can be related to academic engagement. Therefore, the learner's views can be helpful as the beneficiaries of the education.

\section{Methods}

This descriptive-analytic study was conducted on anesthesia and operating room nursing students in the academic year of 2017-2018. The required sample size from each class was selected by simple random sampling from the roll call list. Having at least one semester of academic background at the college and having informed consent to participate in the study were considered as inclusion criteria. Exclusion criterion also included lack of completing the information of questionnaires returned. In order to collect data, the researcher first referred to the education experts of the faculty and collected information about the classroom programs, and subsequently, the instructors of these classes were informed about the goals of the study. Then, the questionnaires were distributed among the volunteer students with the prior coordination with the corresponding professor and obtaining informed consent from the students during the first and last 10 minutes of the class. Also, data was gathered from students who were passing clinical skills in educational courses in educational hospitals with prior notice. Data collection tool included three questionnaires including demographic questionnaire such as age, gender, place of residence, total grade, year of entry, corse experience, and academic engagement questionnaire. In order to assess the teaching quality, Wilson Lizio \& Ramsden's course experience questionnaire (CEQ) was used. This CEQ consists of 36 items and six components, including 1- good teaching (8 items) 2. Clear goals and standards (5 items) 3- Appropriate assessment (6 items), 4- Appropriate workload (5 items) 5Emphasis on independence (6 items), and 6. Generic skills (6 items)[28]. Responses were scored based on 5-point Likert Scale (1. Totally agree to 5.Totally disagree). However, items 10, 15, 16, 17, 18, 19, 20, 21, 23,24 were scored reversely. In this questionnaire, the possible score range was 36 and 180, respectively. Besides, the reliability and validity of CEQ were confirmed by Broomfield and Bly [29]. Abdi et al. (2014) confirmed the validity and reliability of the Persian version of CEQ with Cronbach's alpha coefficient of 95\% [30]. In order to investigate the academic engagement, the academic engagement scale proposed by Schofeli, Leeter, Maslash, and Jackson (1996) was used [31]. This scale consists of 17 items and three constructs of vigor, dedication, and absorption, each with 6,5 , and six questions, respectively. The questions of CEQ are scored based on a 7-point Likert Scale ranging from zero to six. It is worth noting that Schofeli et al. confirmed that reliability of the vigor, dedication, and absorption components with reliability coefficients of $80 \%, 91 \%$, and $75 \%$, respectively [10]. Mohana et al., also reported a reliability coefficient of 0.91 for academic engagement [32].

It should also be noted that among the ethical issues considered in this study included obtaining informed consent from the participants, the anonymity of the questionnaire, the freedom to withdraw from the study. Data analysis was carried out in this study using SPSS ver. 24. Data analysis was carried out in two parts, including descriptive statistics (mean and standard deviation), and analytic statistics 
(one-way analysis of variance, independent t-test, and Pearson correlation). The significance level was considered to be $\mathrm{P}<0.05$.

\section{Results}

In this study, out of a total of 135 students studied, 129 individuals completed the questionnaires, with a response rate of $95 \%$. Of these, five questionnaires were excluded due to missing information, and finally, 124 questionnaires entered statistical analysis phase. The results of the descriptive analysis showed that the mean \pm standard deviation of the age of the subjects was $21.21 \pm 3.08$ years. Also, the number of male and female participants was $38(30.6 \%)$ and $86(69.4 \%)$, respectively. The results showed that 52 $(41.9 \%)$ and $72(58.1 \%)$ of the participants were indigenous and non-indigenous, respectively. Concerning the GPA, 5 (4\%), 23 (18.5\%), and 96 (77.4\%) of the subjects obtained scores ranging 10-14, 14-16, and above 16, respectively. The results of the study on the academic semester of the subjects showed that 42 (33.9\%), 2, 43 (34.7\%), 29 (23.4\%), and 10 (8.1\%) individuals were studying in the fourth, sixth, and eighth semesters, respectively. From the learners' point of view, the degree of satisfaction from the academic period was low, moderate, and optimal in $40.3 \%, 24.4 \%$, and $36.3 \%$ of cases, respectively.

\section{The relationship between academic engagement and teaching quality with demographic and academic variables (Tables 1 and 2)}

The results of one-way ANOVA, which was conducted on the relationship between age, gender, residence status, GPA, and semester status of the subjects with academic engagement and teaching quality, showed statistically significant relationship between the residence status $(P=0.012)$ with academic engagement, and age $(P=0.001)$, and semester status $(P=0.020)$ with teaching quality.

The findings also showed that the mean \pm SD of teaching quality and the academic engagement was $105.60 \pm 15.38$ and was $53.06 \pm 16.80$, respectively. Pearson correlation test also showed a statistically significant difference between mean scores in teaching quality and academic engagement $(P<0.001)$.

\section{The relationship between teaching quality subscales with academic engagement (Table 3)}

The results of Pearson's correlation analysis on the relationship between the teaching quality subscales, including good teaching, clear goals, appropriate assessment, appropriate workload, independence, and generic skills with academic engagement showed a statistically significant relationship between all subscales, except for the proper workload sub-scale $(P=0.234)$. The multivariate linear regression model showed that among the teaching quality subscales, including good teaching, clear goals, appropriate assessment, independence, and generic skills, only two sub-scales of appropriate evaluation $(P=0.002)$ and generic skills $(P=0.043)$ are related to the learners' academic engagement. 


\section{The relationship between the academic engagement subscales with teaching quality (Table 4)}

The results of Pearson correlation analysis on the relationship between the academic engagement subscales, including vigor, dedication, and absorption with teaching quality showed that, except for the absorption subscale $(P=0.058)$, there was a statistically significant relationship between two other subscales. The multivariate linear regression model showed that among the academic engagement subscales, including vigor, dedication, and absorption, only the vigor subscale $(P<0.001)$ is related to the teaching quality of learners.

\section{The relationship between academic engagement and teaching quality with the satisfaction rate}

One-way ANOVA also showed no significant relationship between the degree of satisfaction with the educational course with the teaching quality score $(P=0.821)$ and academic engagement $(P=0.743)$.

\section{Discussion}

The aim of the present study was to investigate the relationship between teaching quality and academic engagement of students of Iran University of Medical Sciences. Overall, the findings of the present research indicate a significant correlation between teaching quality and academic engagement among the above students. The findings of this study were consistent with the results of by Abdi et al.'s research (2014), which investigated the relationship between the course experience and the deliberate practice study approach among nursing students[30]. Overall, in this study, among the course experience subcomponents, good teaching, independence, and clear goals had the most correlation with the academic engagement, which in fact was consistent with the results of Ramsden's study, which examined the relationship between the course experience and the study approach. Ramsden also showed in his study that all appropriate teaching scales, i.e., clear goals and standards, appropriate workload, appropriate assessment, and independence had a positive and significant relationship with deep learning approach[33].

The findings of Shari et al.'s study (2014) also showed that students who choose the active and studentoriented teaching styles have a good academic engagement, which is consistent with the results of the present study, which suggested a positive correlation between the course experience sub-components such as independence and good teaching with a student's academic engagement [34]. Similarly, Downer et al. showed a direct and significant relationship between the teaching style and academic engagement [35]. Janoos also revealed in his study that academic engagement was affected by the teaching style [36]. Doter et al. also suggested a direct and significant relationship between the educational environment and academic engagement [37]. They also showed that academic engagement and achievement would increase in case of optimal teaching quality, the professor-student relationship, and low conflict level. 
The findings of Elina et al.'s study (2016) showed that students' participation and interaction with the education process was useful in terms of academic achievement and progress, and the results of this study showed that the higher the academic engagement is, the higher their academic achievement will be, which is consistent with the current research. However, Ketonen has taken into account the individual differences of the learners, such as the amount of interest, attention, and learning, the physical conditions, such as fatigue, the uncertainty about the professional choice of the university discipline, etc. However, the present study has considered only the components of age, gender, and Indigenous status [38].

Schlenker et al. (2013) also concluded that scientific interaction during teaching process, student academic performance, and academic grades, like a triangular model, could be influenced by each other during the education process, which is consistent with the results of this study, suggesting the impact of teaching quality on the academic engagement [39]. Joyce et al. (2018) also showed in their study that academic engagement is affected by teaching quality; and if the level of intellectual demand of the learners is appropriately measured, it will be effective on the teaching quality and other teaching criteria, and will be significantly correlated with the results of their learning and improved grades [39].

The results of the current study regarding the gender-based evaluation of the academic engagement showed no significant difference between boys and girls in terms of academic engagement. However, Sirin et al. and Folarten also showed that gender was associated with the academic performance and academic engagement, and the level of academic engagement was significantly higher in girls than boys $[37,40]$. Kassos et al. also conducted research on students of the University of Medical Sciences and concluded that the academic engagement of female students was higher than that of male students. They also showed that students with higher academic engagement achieved more favorable academic achievements [41].

One of the limitations of this study is the lack of use of a qualitative research method, along with a quantitative approach, because more complete results can be obtained using qualitative methods such as deep and semi-structured interviews. Also, overlooking the role of the educational environment on the level of academic engagement was also a limitation of the present study. In addition, more significant results could be obtained if this study was conducted in a few specific training groups with a particular unit of course as well as a specific professor. However, the relationship between teaching quality and academic engagement among Iranian students is rarely studied.

Therefore, the results of this study should be compared with the results obtained in other countries and similar domestic studies, which would challenge the results of this study, as there were no researches relevant to the subject of the research.

\section{Conclusion}


Therefore, it can be generally said that there is a significant correlation between course experience and academic engagement and among the course experience-related components, there is a high correlation between good teaching, independence, and clear goals with academic engagement. Thus, it is possible to enhance productivity and improve the quality of the educational system by improving the quality of teaching and thus engaging more students through active and student-centered teaching methods. Therefore, it is essential to plan and implement the education process in order to increase academic engagement and motivation among learners. In general, faculty members and educational staff can predict students' academic failure, or, take measures needed to improve this important variable.

\section{Abbreviation:}

CEQ: course experience questionnaire

\section{Declarations}

Acknowledgments: The researchers would like to thank students who took part in the program. Also, the authors greatly acknowledge Dr Behnaz Rahimi.

Funding: This research did not receive any specific grant from funding agencies in the public, commercial, or not-for-profit sectors.

Availability of data and material: The datasets used and/or analysed during the current study are available from the corresponding author on reasonable request.

Author's Contributions: AH contributed to Conceptualization, Data curation, Investigation, and Writing original draft. EGH contributed to Data curation and Investigation. HA contributed to Conceptualization, and Writing - review \& editing. BA contributed to Supervision and Writing - review \& editing. AHB contributed to Conceptualization, Data curation, Investigation, Analysis, Supervision, and Writing- review \& editing. All authors read and approved the final manuscript.

Consent for publication: Not applicable

Ethical approval and consent to participate: All procedures performed in the present study involving humans were in accordance with the ethical standards of Ethical Committee of Saveh University of Medical Sciences, Tehran, Iran (approval no. IR.SAVEHUMS.REC1395.19). Online consent and a downloadable document was available to participants prior to participation in the study. Also, the authors would like to state that the participants were protected by hiding their personal information during the research process. They knew that their participation was voluntary and provided written informed consent. Furthermore, they could withdraw from the study at any time.

Competing interests: The authors declare that they have no competing interests. 


\section{References}

1. Sun H, Richardson JT. Students' perceptions of the academic environment and approaches to studying in British postgraduate business education. Assessment \& Evaluation in Higher Education. 2016;41(3):384-99.

2. Mok MMC. Quality assurance and school monitoring in Hong Kong. Educational Research for Policy and Practice. 2007;6(3):187-204.

3. Rezaii A, Grami pour M. Structure,factorialvalidityand Reliability ,quality of teaching instrument inthe Behavioral Science. PSYCHOMETRY. 2017;5(20):103-25.

4. Biggs JB. Teaching for quality learning at university: What the student does: McGraw-Hill Education (UK); 2011.

5. Marsh HW, Morin AJ, Parker PD, Kaur G. Exploratory structural equation modeling: An integration of the best features of exploratory and confirmatory factor analysis. Annual review of clinical psychology. 2014;10:85-110.

6. van Uden JM, Ritzen H, Pieters JM. Engaging students: The role of teacher beliefs and interpersonal teacher behavior in fostering student engagement in vocational education. Teaching and Teacher Education. 2014;37:21-32.

7. Richardson JT. Students' perceptions of academic quality and approaches to studying in distance education. British Educational Research Journal. 2005;31(1):7-27.

8. Janosz M, Le Blanc M, Boulerice B, Tremblay RE. Predicting different types of school dropouts: A typological approach with two longitudinal samples. Journal of educational psychology. 2000;92(1):171.

9. Fredricks JA, Blumenfeld PC, Paris AH. School engagement: Potential of the concept, state of the evidence. Review of educational research. 2004;74(1):59-109.

10. Schaufeli WB, Martinez IM, Pinto AM, Salanova M, Bakker AB. Burnout and engagement in university students: A cross-national study. Journal of cross-cultural psychology. 2002;33(5):464-81.

11. Alrashidi O, Phan HP, Ngu BH. Academic engagement: an overview of its definitions, dimensions, and major conceptualisations. International Education Studies. 2016;9(12):41.

12. Linnenbrink EA, Pintrich PR. The Role of Self-Efficacy Beliefs Instudent Engagement and Learning Intheclassroom. Reading \&Writing Quarterly. 2003;19(2):119-37.

13. Finlay KA. Quantifying school engagement: Research report. Denver, CO: National Center for School Engagement. 2006. 
14. Farhadi ALI, Saki kourosh, Ghadampour Ezatollah, Khalili Geshnigani Zahra, Parastoo C. Predictions dimensions of academic engagement based capital components psychological. Educational Strategies Journal. 2016;9(2):123-7.

15. Zadeh AS, Abedi A, Yousefi Z, Aghababaei S. The Effect of Successful Intelligence Training Program on Academic Motivation and Academic Engagement Female High School Students. International Journal of Psychological Studies. 2014;6(3):118.

16. Mahmoodi N, Naziri G, Zarenezhad M. A Comparison of Attachment Styles and Identity Styles in People with Gender Dysphoria Disorder (Operated and Not Operated) and Normal People in Southwest of Iran In 2014. Mediterranean Journal of Social Sciences. 2015;6(6 S6):381.

17. Furrer C, Skinner E. Sense of relatedness as a factor in children's academic engagement and performance. Journal of educational psychology. 2003;95(1):148.

18. Reeve J. A self-determination theory perspective on student engagement. Handbook of research on student engagement: Springer; 2012. p. 149-72.

19. Appleton JJ, Christenson SL, Kim D, Reschly AL. Measuring cognitive and psychological engagement: Validation of the Student Engagement Instrument. Journal of school psychology. 2006;44(5):427-45.

20. Saber Susan, Hasan PS. Predicting dimensions of academic engagement by identity styles in first grade girl students of tehran state high schools. Curriculum Planning Knowledge and Research in Educational Sciences. 2013;10(11(38)):72-85.

21. Shaari AS, Yusoff NM, Ghazali IM, Osman RH, Dzahir NFM. The relationship between lecturers' teaching style and students' academic engagement. Procedia-Social and Behavioral Sciences. 2014;118:10-20.

22. Janosz M, Archambault I, Morizot J, Pagani LS. School engagement trajectories and their differential predictive relations to dropout. Journal of social Issues. 2008;64(1):21-40.

23. Shana ZA, Abulibdeh ES. Engaging students through blogs: Using blogs to boost a course experience. International Journal of Emerging Technologies in Learning (iJET). 2015;10(1):30-8.

24. Wang M-T, Eccles JS. School context, achievement motivation, and academic engagement: A longitudinal study of school engagement using a multidimensional perspective. Learning and Instruction. 2013;28:12-23.

25. Haghani F, Chavoshi E, Valiani A, Yarmohammadian MH. Teaching Styles of Teachers in Basic Sciences Classes in Medical School of Isfahan University of Medical Sciences. Iranian Journal of Medical Education. 2011;10(5). 
26. Azizi Khalkheili t, a. h. Factors affecting teaching quality of faculty members in sari agricultural sciences and natural resources university from students' and graduates' perspective. Iranian Agricultural Extension and Education Journal. 2016;12(1):165-79.

27. Fenn AJ. Student evaluation based indicators of teaching excellence from a highly selective liberal arts college. International Review of Economics Education. 2015;18:11-24.

28. Wilson KL, Lizzio A, Ramsden P. The development, validation and application of the Course Experience Questionnaire. Studies in higher education. 1997;22(1):33-53.

29. Broomfield D, Bligh J. An evaluation of theshort form'course experience questionnaire with medical students. Medical Education. 1998;32(4):367-9.

30. Abdi H, Nilli MR. The Relationship between Course Experience and Deliberate Practice Study Approach among Nursing Students. Iranian Journal of Medical Education. 2014;14(9):758-66.

31. Maslach C, Jackson SE, Leiter MP. Maslach burnout inventory manual: Consulting psychologists press Palo Alto, CA; 1996.

32. Mohanna S, Talepasand S. The Relationship between Environmental Supports and Emotional Selfawareness with Academic Engagement: the Mediating role of Educational Well-being. Iranian Journal of Medical Education. 2016;16:31-42.

33. Ramsden P. A performance indicator of teaching quality in higher education: The Course Experience Questionnaire. Studies in higher education. 1991;16(2):129-50.

34. Shaari AS YN, Ghazali IM, Osman RH, Dzahir NFM. The relationship between lecturers' teaching style and students' academic engagement. Procedia-Social and Behavioral Sciences. 2014;118:10-20.

35. Downer JT R-KS, Pianta RC. How do classroom conditions and children's risk for school problems contribute to children's behavioral engagement in learning? School Psychology Review. 2007;36(3):413.

36. Janosz M Al, Morizot J, Pagani LS. School engagement trajectories and their differential predictive relations to dropout. Journal of social Issues. 2008;64(1):21-40.

37. Sirin SR, Rogers-Sirin L. Components of school engagement among African American adolescents. Applied Developmental Science. 2005;9(1):5-13.

38. Ketonen EE H-MA, Hirsto L, Hänninen JJ, Wähälä K, Lonka K. Am I in the right place? Academic engagement and study success during the first years at university. Learning and Individual Differences. 2016 Oct 1;51:141-8.

39. Joyce J GD, laconangelo CJ. Classroom assignments as measures of teaching quality. Learning and instruction. 2018 Apr 1;54:48-61. 
40. Fullarton S. Student Engagement with School: Individual and School-Level Influences. Longitudinal Surveys of Australian Youth. . Research Report. 2002;27.

41. Casuso-Holgado MJ C-VA, Moreno-Morales N, Labajos-Manzanares MT, Barón-López FJ, Vega-Cuesta $M$. The association between academic engagement and achievement in health sciences students. BMC medical education. 2013;13(1):33.

\section{Tables}

Table 1 Difference between sub-variables of academic engagement according to demographic and academic variables

\begin{tabular}{|c|c|c|c|c|}
\hline Variable & Demographic and Academic variables & & Mean \pm SEM & P-value \\
\hline \multirow{14}{*}{ academic engagement } & \multirow{3}{*}{ Age } & $19>$ & $59 / 17 \pm 08 / 50$ & \multirow[t]{3}{*}{$169 / 0$} \\
\hline & & $20-24$ & $09 / 15 \pm 30 / 55$ & \\
\hline & & $24<$ & $98 / 24 \pm 20 / 59$ & \\
\hline & \multirow[b]{2}{*}{ Sex } & Male & $21 / 16 \pm 39 / 54$ & $560 / 0$ \\
\hline & & female & $11 / 17 \pm 47 / 52$ & \\
\hline & \multirow[t]{2}{*}{ nativity status } & indigenous & $62 / 14 \pm 50 / 57$ & \multirow[t]{2}{*}{$012 / 0$} \\
\hline & & non-indigenous & $63 / 17 \pm 86 / 49$ & \\
\hline & \multirow{3}{*}{ average } & $14-10$ & $65 / 9 \pm 60 / 62$ & \multirow[t]{3}{*}{$294 / 0$} \\
\hline & & $16-14$ & $04 / 18 \pm 86 / 49$ & \\
\hline & & $16<$ & $70 / 16 \pm 33 / 53$ & \\
\hline & \multirow{4}{*}{ academic semester } & 2 & $31 / 15 \pm 40 / 50$ & \multirow[t]{4}{*}{$202 / 0$} \\
\hline & & 4 & $70 / 17 \pm 39 / 51$ & \\
\hline & & 6 & $31 / 18 \pm 27 / 57$ & \\
\hline & & 8 & $81 / 11 \pm 20 / 59$ & \\
\hline
\end{tabular}


Table 2 Difference between sub-variables of teaching quality according to demographic and academic variables

\begin{tabular}{|c|c|c|c|c|}
\hline Variable & Demographic and Academic variables & & Mean \pm SEM & P-value \\
\hline \multirow{14}{*}{ teaching quality } & \multirow[b]{4}{*}{ nativity status } & male & $96 / 13 \pm 55 / 106$ & \multirow[t]{2}{*}{$605 / 0$} \\
\hline & & female & $02 / 16 \pm 18 / 105$ & \\
\hline & & indigenous & $71 / 16 \pm 96 / 107$ & \multirow[t]{2}{*}{$148 / 0$} \\
\hline & & non-indigenous & $21 / 14 \pm 90 / 103$ & \\
\hline & \multirow{3}{*}{ age } & $19>$ & $26 / 16 \pm 31 / 100$ & \multirow[t]{3}{*}{$001 / 0$} \\
\hline & & $20-24$ & $92 / 12 \pm 67 / 110$ & \\
\hline & & $24<$ & $93 / 14 \pm 00 / 103$ & \\
\hline & \multirow{3}{*}{ average } & $14-10$ & $61 / 10 \pm 20 / 113$ & \multirow[t]{3}{*}{$511 / 0$} \\
\hline & & $16-14$ & $19 / 14 \pm 43 / 104$ & \\
\hline & & $16<$ & $86 / 15 \pm 48 / 105$ & \\
\hline & \multirow{4}{*}{ academic semester } & 2 & $54 / 16 \pm 00 / 100$ & \multirow[t]{4}{*}{$020 / 0$} \\
\hline & & 4 & $56 / 14 \pm 55 / 108$ & \\
\hline & & 6 & $56 / 14 \pm 82 / 106$ & \\
\hline & & 8 & $20 / 9 \pm 90 / 112$ & \\
\hline
\end{tabular}

Table 3 The correlation between academic engagement and sub-scale of teaching quality 


\begin{tabular}{|c|c|c|c|c|c|c|c}
\hline $\begin{array}{c}\text { appropriate } \\
\text { teaching }\end{array}$ & $\begin{array}{c}\text { Clear } \\
\text { goals }\end{array}$ & $\begin{array}{c}\text { appropriate } \\
\text { assessment }\end{array}$ & $\begin{array}{c}\text { appropriate } \\
\text { workload }\end{array}$ & independence & $\begin{array}{c}\text { general } \\
\text { skills }\end{array}$ & variables \\
\hline $003 / 0$ & $022 / 0$ & $002 / 0$ & $234 / 0$ & $013 / 0$ & $046 / 0$ & P-value & academic \\
\hline $266 / 0$ & $205 / 0$ & $279 / 0$ & $108 / 0$ & $224 / 0$ & $180 / 0$ & correlation & engagement \\
& & & & & coefficient & \\
\hline
\end{tabular}

Table 4 The correlation between teaching quality and sub-scale of academic engagement

\begin{tabular}{|c|c|c|c|c}
\hline vigor & dedication & absorption & & variables \\
\hline $001 / 0>$ & $001 / 0$ & $058 / 0$ & P-value & \multirow{2}{*}{ teaching quality } \\
\hline $368 / 0$ & $286 / 0$ & $171 / 0$ & correlation coefficient & \\
\hline
\end{tabular}

